\title{
A New Alloy of High Density
}

\author{
By Dr. C. J. Smithells
}

$\mathrm{T}$ $\mathrm{HE}$ use of large masses of radium in beam therapy necessitates the provision of adequate protection. At the same time, the actual container should be as small as possible if the radium is to be used efficiently, particularly in inaccessible positions. Absorption of the harmful $\gamma$-radiation by metals is directly proportional to their density, and for this reason a smaller container, or bomb, can be used if it is made of a metal of high density. The bomb and nose-piece, to give the necessary protection, weigh 50-100 lb. and have usually been made of lead, which has a density of 11.35

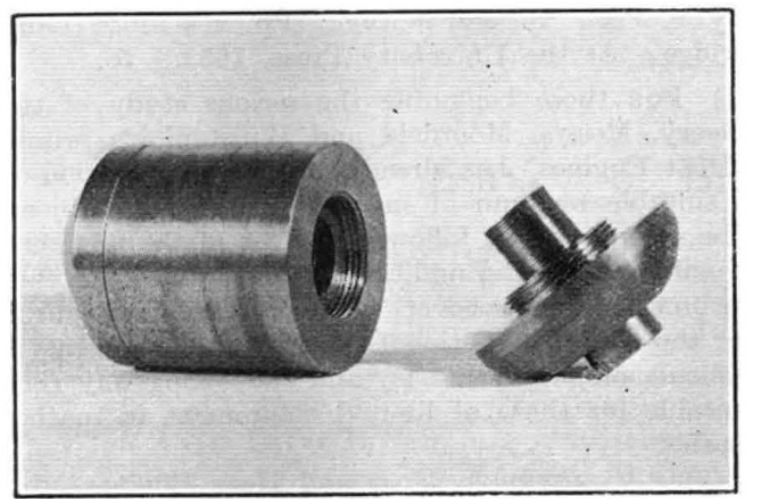

Fig. 1.

Tungsten Alloy Radium Container.

gm./c.c. The actual nose-piece has sometimes been made of gold, but this metal is too expensive to be used for the bomb itself.

The problem of producing an alloy of high density at a reasonable cost was suggested to me by the late Sir John McLennan. The only metal which is reasonably cheap, having a density comparable with that of gold, is tungsten; but a high density is only attained when the metal has been sintered at about $3000^{\circ} \mathrm{C}$., and no means are available for heating masses approaching $1 \mathrm{cwt}$. to such a high temperature.

The problem has been solved at the Research Laboratories of the General Electric Co. at Wembley by mixing tungsten powder with a small proportion of a metal of lower melting point, so that a liquid phase is formed on heating to a moderate temperature. If the tungsten particles are wetted by the liquid metal, shrinkage results, and densities closely approaching the theoretical are obtained. Either nickel or copper are suitable additions for this purpose. Copper melts at $1084^{\circ} \mathrm{C}$., whilst nickel and tungsten form a eutectic melting at just above $1400^{\circ} \mathrm{C}$. If the heating is carried out in an atmosphere of hydrogen, the tungsten particles are wetted in both cases. 5-10 per cent of either nickel or copper powders, or a mixture of the two, is added to the tungsten powder, which is then pressed to the required shape in a steel die and heated in hydrogen at $1450^{\circ} \mathrm{C}$. for an hour. Since a linear shrinkage of about twenty per cent occurs during sintering, allowance must be made for this in designing the dies.

The alloy generally used for radium bombs contains 5 per cent copper and 5 per cent nickel, and the density of the finished pieces lies between 16.3 and $16.5 \mathrm{gm} . / \mathrm{c} . \mathrm{c}$. With a smaller proportion of added metal it is possible to obtain densities in excess of 17. The density of the new alloys is therefore fifty per cent greater than that of lead, and a corresponding reduction in the size of the bomb is possible.

The microstructure shows particles of tungsten embedded in a matrix of copper, copper-nickel, or nickel-tungsten according to the composition employed. Although tungsten itself is practically not machinable, the alloys can be readily machined with ordinary tools, drilling, tapping and screwcutting presenting no difficulties. Where large surfaces have to be machined, it is an advantage to use a tool of the cemented tungsten carbide type.

Owing to the difficulty of pressing very thick sections, it has been found most economical to construct radium bombs by welding together a number of annular rings. These may be up to one inch thick and five inches in diameter. Their surfaces are accurately machined and then placed on one another with $0.1 \mathrm{~mm}$. nickel foil between them. On heating to $1450^{\circ} \mathrm{C}$. in hydrogen, the nickel melts and forms a perfect weld. A complete bomb is shown in Fig. 1. About ten bombs have now been made in this way and are in use in various hospitals in Great Britain. One or two installations employing them have already been referred to in NATURE ${ }^{\mathbf{1}}$.

Although developed primarily for radium work, tungsten alloys made on this principle are finding several industrial applications. An alloy of this type has been used successfully for balancing crankshafts for internal combustion engines used in racing motor-cars. It seems likely to find a similar application in aircraft engines. It has 
also been used in gyroscopes and for similar purposes where high density combined with strength is necessary. The tensile strength of the sintered alloys is about twenty-two tons per square inch, but although they can be hot worked, they have very little ductility cold.

The largest application, however, is as a contact material for heavy-current circuit breakers. For this purpose, the alloy is applied as a facing brazed on to the copper contact arms. Contacts having a superficial area of about two square inches have been used successfully to break currents of 130,000 amperes at 6,000 volts. Tungsten has, of course, long been recognized as a useful contact material, owing to its low vapour pressure, but the pure metal could not be produced economically in the large sections required for high-power electrical engineering purposes.

1 NATURe, 139, 52 (1937).

\section{The Starling in the United States of America}

\section{By Dr. Walter E. Collinge}

$\mathrm{T}$ $\mathrm{HE}$ dangers arising from the introduction of foreign species of animals have frequently been dwelt upon by zoologists of all nationalities. The results of such acclimatizations have nowhere been more pertinently summarized than by Palmer ${ }^{1}$ in 1893.

The species to which we here wish to direct attention is the European starling (Sturnus vulgaris Linn.). Thirty-five years ago we possessed a very meagre knowledge of the feeding habits and economic status of this bird, and it was introduced into various countries in the belief that it was distinctly beneficial to the farmer and fruitgrower.

The earliest record I can find of its introduction into the United States is that made by the Acclimatization Society of Cincinnati, Ohio, which liberated a number in the winter of 1872-73. In 1877 the American Acclimatization Society liberated a number in Central Park, New York, and again in 1890 about sixty birds were released. In 1889 and 1892 thirty-five pairs are reported to have been released at Portland, Oregon. In April 1890 eighty birds were released in Central Park, New York, and forty more in March of the following year. Later, smaller numbers were liberated in different localities.

From these various importations the starling has increased and spread throughout the whole of the north-eastern States, and it is gradually spreading westwards. The extension of the range and the methods of spread have been fully dealt with by Mrs. Mary Thacker Cooke ${ }^{2}$, while a fully detailed account of the food and feeding habits has been published by Kalmbach and Gabrielson ${ }^{3}$. To this latter I shall refer later.

Few seem to have regarded the starling as a potential danger to the United States. Writing in 1916, Forbush" stated, "Already the starling has begun to show a capacity for harmfulness which may be expected to become more prominent as its numbers increase. . . Perhaps it is too early yet to say what will be the final result of the introduction of the starling into this country. Its value as an insect destroyer is plain; but its unchecked increase may prove a calamity to several species of useful native birds, and from the experience of other countries we may assume that it is likely to become a pest to the fruit grower."

In any attempt to arrive at the true economic position of this bird, we must not lose sight of the fact that it is a powerful animal with a strong and formidable weapon of defence in the shape of its beak. Moreover, it exhibits great powers of caution and intelligence.

A further point of interest is its great fecundity ; it is exceedingly difficult to estimate even approximately the actual number of pairs of breeding birds in the United States; but for the purpose of illustrating the rate of increase, we will presume that in 1933 there were 200,000 pairs, and that each pair reared three pairs of young, half of each sex, and that all lived together with their offspring. The progeny and parents in a single year would total 1,600,000. At the end of 1934 this number would have increased to $6,400,000$, the addition in 1935 would make the total $25,600,000$, while at the end of 1936 there would be more than $102,000,000$ birds.

These figures are calculated on the basis of a single brood per year, though in many parts of the country there are two broods. Even allowing for a very high rate of mortality, it is clear that the annual increase is enormous. Herein lies a potential danger which should not be overlooked.

Knowing how injurious this bird has become in Great Britain and also in Australia, New Zealand 